\title{
Miniaturized Domain Engineered Multilayer Actuators
}

\author{
B.A. Tuttle, P. Yang, M. F. Bourbina, E.L. Venturini, S.D. Nicolaysen, W. Olson, and G. A. Samara \\ Sandia National Laboratories, \\ MS1405, 1515 Eubank Blvd. SE, Albuquerque, NM 87185, USA \\ Batutt1@sandia.gov
}

Abstract - PMN/PT 67/33 <100> single crystals were evaluated under high drive conditions from ambient to $80^{\circ} \mathrm{C}$ for miniaturized multilayer actuator (MLA)applications. Multilayer actuators were fabricated under identical processing conditions using two different materials: (1) single crystal PMN/PT (SCPMN) and (2) hot-pressed PZT-5A. Five layer SCPMN actuators with individual element sizes of 3 $\mathrm{mm} \times 3 \mathrm{~mm} \mathrm{X} 0.25 \mathrm{~mm}$ have measured displacements on the order of $3 \mu \mathrm{m}$ at $20 \mathrm{kV} / \mathrm{cm}$ unipolar field. While superior strain behavior was observed for the PMN/PT single crystals at ambient, at higher operating temperatures $\left(50^{\circ} \mathrm{C}\right.$ to $\left.80^{\circ} \mathrm{C}\right)$, the performance declined. Insights into both device performance and the different physics governing normal ferroelectric and domain engineered materials with temperature were obtained by two techniques: (1) high field ac impedance analysis $(0.6$ to $8 \mathrm{kV} / \mathrm{cm} \mathrm{ac})$ and (2) analysis of dielectric transformation behavior with hydrostatic pressure $(0$ to $2 \mathrm{GPa}$ ).

\section{INTRODUCTION}

Single crystal ferroelectrics, such as, lead zinc niobate / lead titanate (PZN/PT) and lead magnesium niobate lead titanate (PMN/PT) have received much recent study because of 5 to 10 times larger piezoelectric constants and $30 \%$ larger electromechanical coupling coefficients [1-3] than commercial lead zirconate titanate materials. Piezoelectric response is maximized for crystals with rhombohedral structure that are $\langle 100\rangle$ oriented. The largest piezoelectric constants are obtained for compositions near the rhombohedral - tetragonal morphotropic phase boundary. Studies by Park and coworkers [1] indicate that with increasing field three different types of strain versus field behavior are observed. The mechanisms responsible for this strain behavior with increasing field are: (1) polarization orientation in the rhombohedral state (Region A), (2) rhombohedral to tetragonal field induced phase transformation (Region B) and (3) normal ferroelectric tetragonal phase piezoelectric behavior. Strains greater than $1 \%$ under high field have been achieved. Because $\mathrm{PMN} / \mathrm{PT}$ melts congruently, it is easier and more cost effective to grow large, high quality single crystal
PMN/PT than PZN/PT. For this reason, our work is $S \mathrm{TI}$ based on single crystal lead magnesium niobate lead titanate crystals.

Ferroelectric single crystals have been mainly targeted for medical ultrasound [4] and sonar [5] applications. The principal application for our work is the development of miniaturized actuators for LIGA based electromechanical systems. Specifically, fundamental material properties, such as, friction, fracture toughness and mechanical strength need to be determined in the LIGA size range to develop a tool set that would permit efficient development of new miniaturized electromechanical systems. Miniaturized actuators with large displacements that operate at temperatures up to $80^{\circ} \mathrm{C}$ are needed to determine these fundamental properties. Displacements in excess of 20 $\mu \mathrm{m}$ from a $5 \mathrm{~mm}$ long actuator are desired.

An understanding of the effects of temperature, electric field and pressure on phase transformation behavior of SCPMN is necessary to optimize LIGA electromechanical device performance. Single crystal PMN/PT 67/33 ferroelectrics exhibit the following phase transitions with increasing temperature:

(1) rhombohedral to tetragonal (R to T) $\left(\sim 80^{\circ} \mathrm{C}\right)$ and

(2) tetragonal to cubic $\left(145^{\circ} \mathrm{C}\right)$.

Recent work by Samara and Venturini [6] on PZN/PT 90.5/9.5 crystals, which exhibit similar phase transformation behavior to SCPMN, has shown substantial decrease in $\mathrm{Tc}\left(6.6^{\circ} \mathrm{C} / 0.1 \mathrm{GPa}\right)$ and an increase in the rhombohedral to tetragonal transformation temperature with hydrostatic pressure (approximately $3^{\circ} \mathrm{C} / 0.1 \mathrm{GPa}$ ). While the Curie point was shown to increase with electric field $(4 \mathrm{kV} / \mathrm{cm})$, the rhombohedral to tetragonal transition temperature decreased. For high drive actuators, the transition behavior with field is a concern. The field and strain regime of high piezoelectric response, before the material transforms to the relatively low piezoelectric response tetragonal phase, may be quite limited. Thus, a goal of our work was to investigate both strain versus field and dielectric behavior in the vicinity of the rhombohedral to tetragonal transformation temperature. 


\section{DISCLAIMER}

This report was prepared as an account of work sponsored by an agency of the United States Government. Neither the United States Government nor any agency thereof, nor any of their employees, make any warranty, express or implied, or assumes any legal liability or responsibility for the accuracy, completeness, or usefulness of any information, apparatus, product, or process disclosed, or represents that its use would not infringe privately owned rights. Reference herein to any specific commercial product, process, or service by trade name, trademark, manufacturer, or otherwise does not necessarily constitute or imply its endorsement, recommendation, or favoring by the United States Government or any agency thereof. The views and opinions of authors expressed herein do not necessarily state or reflect those of the United States Government or any agency thereof. 


\section{DISCLAIMER}

Portions of this document may be illegible in electronic image products. Images are produced from the best available original document. 


\section{EXPERIMENTAL PROCEDURE}

PMN / PT 63/37 single crystals were obtained from H. C. Materials Corporation, Urbana, IL, in the form of $6.3 \mathrm{~mm} \times 6.3 \mathrm{~mm} \times 0.25 \mathrm{~mm}$ plates. The PZT-5A ceramics were hot-pressed at $1200^{\circ} \mathrm{C}$ for 12 hours to greater than $99 \%$ density. Individual piezoelectric chips for our 5 element multilayer actuators were diced from $0.25 \mathrm{~mm}$ thick wafers of piezoelectric material using a precision dicing system (Kulicke \& Soffa model 982-6). Dimensions of the individual chips were approximately ( $3 \mathrm{~mm} \mathrm{X} 3 \mathrm{~mm} \mathrm{X} 0.25 \mathrm{~mm}$ ) with the lateral dimensions of the chips held to within $0.010 \mathrm{~mm}$ of the nominal value. Laser machined alumina masks were used to define alternately placed electrode tabs on each chip. The electrodes were deposited by airbrush deposition of Dupont 4817 silver paste. A nonconductive epoxy (The Dexter Company 0151) was used to contact the chips with light mechanical lamination pressure. While Dupont $4922 \mathrm{~N}$ silver paste was used to make electrical contact to the alternate edges of the electrodes, Dupont 3025 silver epoxy was used to bond Kovar test leads to the MLAs for external measurements.

Simultaneous strain and dielectric hysteresis measurements were made with a Radiant Technologies RT6000HVS ferroelectric tester in conjunction with a MTI-2000 photonic sensor. An HP4194A high frequency impedance analyzer was modified to permit application of up to 200 volt peak to peak test voltages in addition to the normal 0.5 volt test voltages. Impedance analyses for ac fields up to $8 \mathrm{kV} / \mathrm{cm}$ were performed on $6 \mathrm{~mm}$ diameter X $0.25 \mathrm{~mm}$ thick disks of SCPM. Dielectric analyses as a function of hydrostatic pressure ( 0 to $2 \mathrm{GPa}$ ), frequency $(100 \mathrm{~Hz}$ to $100 \mathrm{kHz}$ ) and temperature $\left(-100^{\circ} \mathrm{C}\right.$ to $\left.150^{\circ} \mathrm{C}\right)$ were performed using an HP4192A LCR meter. Pressure was generated using conventional high pressure apparatus using either a 50/50 mixture of normal- and iso-pentanes or helium gas as the pressure transmitting media.

\section{RESULTS AND DISCUSSION}

Strain versus electric field characteristics for the five element SCPMN and PNZT2/52/48 multilayer actuators are shown in Fig.1. Both MLAs showed approximately linear behavior, with the SCPMN actuator having 2.5 times more strain at $20 \mathrm{kV} / \mathrm{cm}$ ( $0.23 \%$ compared to $0.089 \%$ strain). Effective piezoelectric coefficients of 1155 and $450 \mathrm{pC} / \mathrm{N}$ are calculated from the strain data. Strain versus $20 \mathrm{kV} / \mathrm{cm}$ field measurements were performed at $60^{\circ} \mathrm{C}, 70^{\circ} \mathrm{C}$ and $75^{\circ} \mathrm{C}$. The SCPMN MLA exhibited about 3 times greater strain than the PZT MLA. Measurements of our individual PZT and SCPMN chips showed reduced piezoelectric response compared to larger bulk specimens $(10 \times 10 \times 1 \mathrm{~mm})$. Specifically, individual chips had direct measured $d_{33}$ of $320 \mathrm{pC} / \mathrm{N}$ and 1200 $\mathrm{pC} / \mathrm{N}$ compared to values of 400 and $2200 \mathrm{pC} / \mathrm{N}$ for the larger pieces. Electroding or slicing damage are possible causes for this degradation.

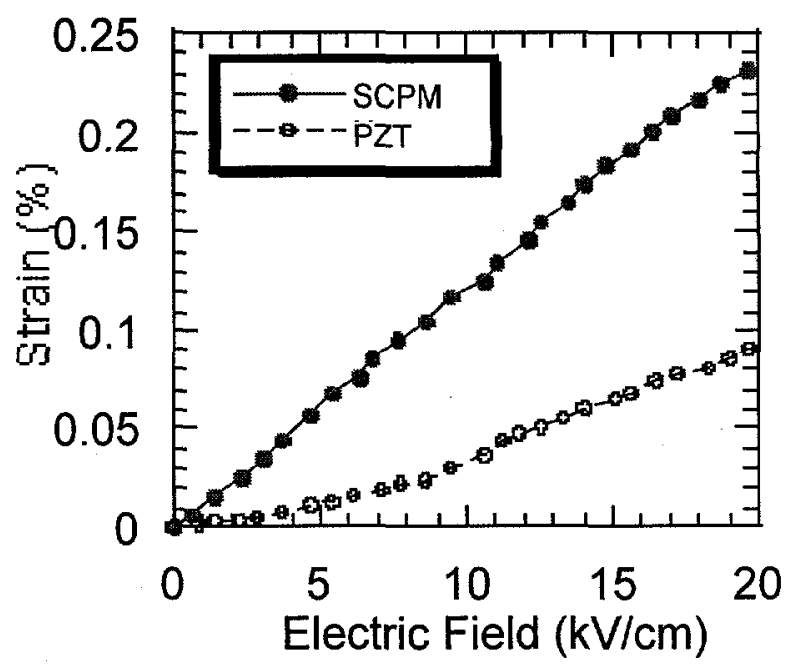

Fig. 1. Strain versus electric field for SCPMN and PZT$5 \mathrm{~A}$ multilayer actuators at $25^{\circ} \mathrm{C}$.

Individual chips were investigated to develop a better understanding of the materials cause for this degradation of the SCPMN MLA at large strains and high temperatures. Using the $K \& S$ precision dicing system, chips as small as $1 \mathrm{~mm} \mathrm{X} 1 \mathrm{~mm} \times 0.14 \mathrm{~mm}$ were demonstrated to have excellent dielectric hysteresis properties as shown in Fig. 2. Sputtered electrodes of $\mathrm{Ti} / / \mathrm{Au}$ were used for these samples. Fields of $66 \mathrm{kV} / \mathrm{cm}$ were applied without breakdown of these parts of suitable size for high resolution ultrasound applications.

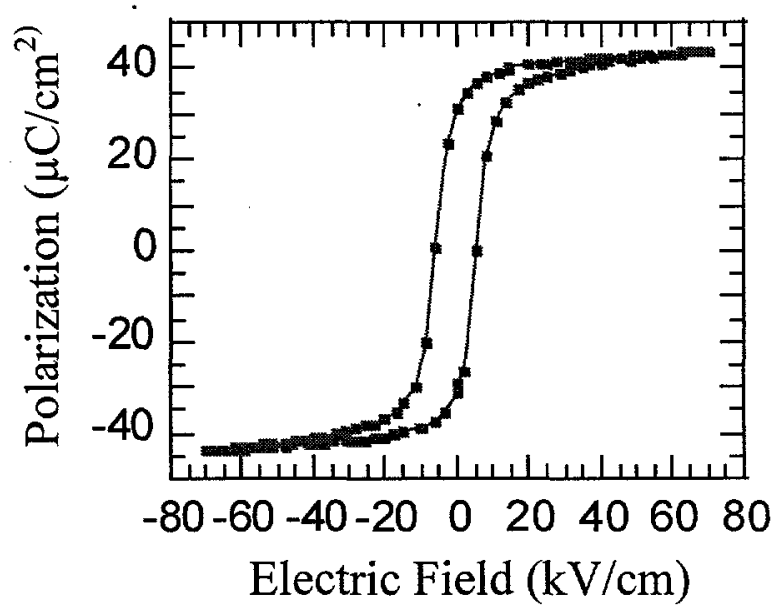

Fig. 2 Polarization versus electric field for $0.14 \mathrm{~mm}$ thick SCPMNPT single crystal.

Strain versus field for a $1 \mathrm{~mm}$ thick SCPMN specimen at $60^{\circ} \mathrm{C}$ and $75^{\circ} \mathrm{C}$ is shown in Fig, 3. As temperature increases from $25^{\circ} \mathrm{C}$, the low field piezoelectric constants increase substantially. The respective piezoelectric coefficients for region $\mathrm{A}$ and region $\mathrm{B}$ at $75^{\circ} \mathrm{C}$ are 3900 and $8000 \mathrm{pC} / \mathrm{N}$. However above $0.22 \%$ strain the tetragonal phase, with a much lower $d_{33}$ of $430 \mathrm{pC} / \mathrm{N}$, is induced. Strain vs. field characteristics were measured at $5^{\circ} \mathrm{C}$ increments from 
$50^{\circ} \mathrm{C}$ to $80^{\circ} \mathrm{C}$ to determine the electric field range of stability of the high piezoelectric response phases. The field range increases from $0 \mathrm{kV} / \mathrm{cm}$ at $80^{\circ} \mathrm{C}$ to $20 \mathrm{kV} / \mathrm{cm}$ at $50^{\circ} \mathrm{C}$. There is roughly an increase of $1.3 \mathrm{kV} / \mathrm{cm} /{ }^{\circ} \mathrm{C}$ in field stability range as temperature decreases from

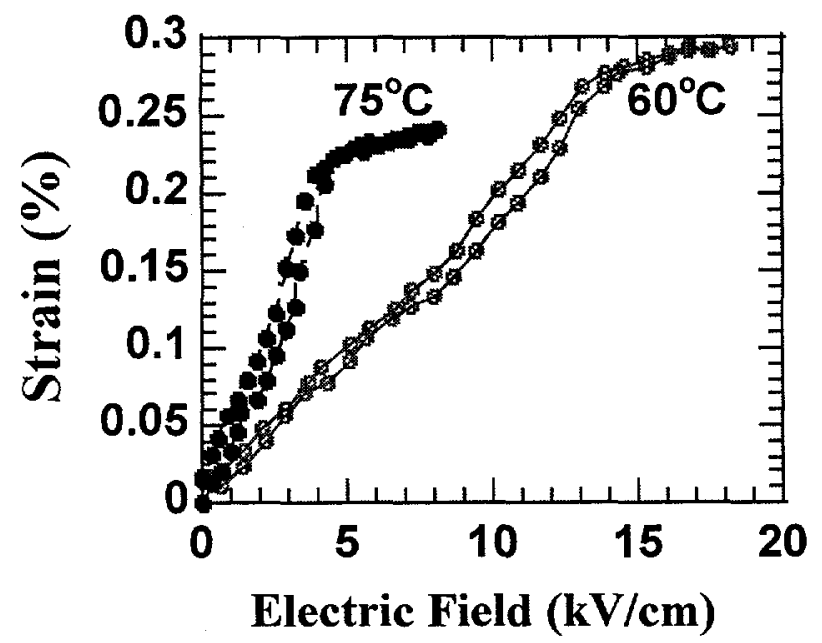

Fig. 3. Strain versus field for SCPMN at $60^{\circ} \mathrm{C}$ and $75^{\circ} \mathrm{C}$.

$75^{\circ} \mathrm{C}$ to $50^{\circ} \mathrm{C}$. Although the increased piezoelectric constants of SCPMN provide greater displacement at 20 $\mathrm{kV} / \mathrm{cm}$ fields, the difference in strain performance compared to PZT-5A should be less for operating fields in excess of $20 \mathrm{kV} / \mathrm{cm}$. More importantly for device applications, the PZT-5A materials do not have a phase transformation at $80^{\circ} \mathrm{C}$ as does SCPMN.

Greater insight into the material aspects of the high temperature SCPMN strain behavior was determined by dielectric characterization as a function of hydrostatic pressure. The Curie point decreased as a function of pressure from $145^{\circ} \mathrm{C}$ at atmospheric pressure to $57^{\circ} \mathrm{C}$ at $2 \mathrm{GPa}$ with a linear change of $4.5^{\circ} \mathrm{C} / 0.1 \mathrm{GPa}$. This rate of change is comparable to other perovskite materials, such as, $\mathrm{BaTiO}_{3}[7]$ which has a $5.2^{\circ} \mathrm{C} / 0.1 \mathrm{GPa}$ decrease in Curie point with hydrostatic pressure. Interestingly, for the SCPMN crystals, the initial onset of the ferroelectric to relaxor crossover occurs at $2.0 \mathrm{GPa}$, as there is a $2^{\circ} \mathrm{C}$ difference in $\mathrm{Tc}$ measured at $1 \mathrm{kHz}$ and $100 \mathrm{kHz}$. For PZN/PT 90.5/9.5 crystals, [4] which are much closer to the morphotropic phase boundary, strong relaxor behavior was observed at lower pressure $(0.5$ $\mathrm{GPa}$ ) as expected.

The $\mathrm{R}$ to $\mathrm{T}$ transition temperature and characteristics were very dependent on thermal history. For example, the structure of the $\mathrm{R}$ to $\mathrm{T}$ transformation decreased when temperature ranges from $-90^{\circ} \mathrm{C}$ to $200^{\circ} \mathrm{C}$, rather than $25^{\circ} \mathrm{C}$ to $200^{\circ} \mathrm{C}$, were investigated. Our study emphasized dielectric measurements with temperature cycles from $25^{\circ} \mathrm{C}$ to $150^{\circ} \mathrm{C}$ at a rate of $1^{\circ} \mathrm{C}$ per minute to correlate with our strain measurements. Unpoled samples exhibited a $\mathrm{R}$ to $\mathrm{T}$ transition temperature of $72^{\circ} \mathrm{C}$ to $80^{\circ} \mathrm{C}$ at ambient pressure. Poled samples had substantially more structure associated with the transition than unpoled samples. Specifically, a more abrupt transition at $80^{\circ} \mathrm{C}$ ( $\mathrm{R}$ to $\mathrm{T}$ transformation) and another peak at $98^{\circ} \mathrm{C}$ (possibly due to domain reorientation) were observed for the poled sample. Poled (0.1 MPa) versus unpoled (500 MPa) dielectric constant behavior is shown in Fig. 4. Pressures up to $500 \mathrm{MPa}$ to first order did not change the dual features of the transition for poled samples. As for previous work on SCPZN [4], there was far more scatter in the pressure vs. $R$ to $T$ transformation data, than for the Curie point pressure data. While we could not definitively state how pressure affects the $\mathrm{R}$ to $\mathrm{T}$ transformation temperature for SCPMN, slight increase in $\mathrm{R}$ to $\mathrm{T}$ transformation temperature $\left(2.7^{\circ} \mathrm{C} / 0.1 \mathrm{GPa}\right)$ was observed [4] for SCPZN.

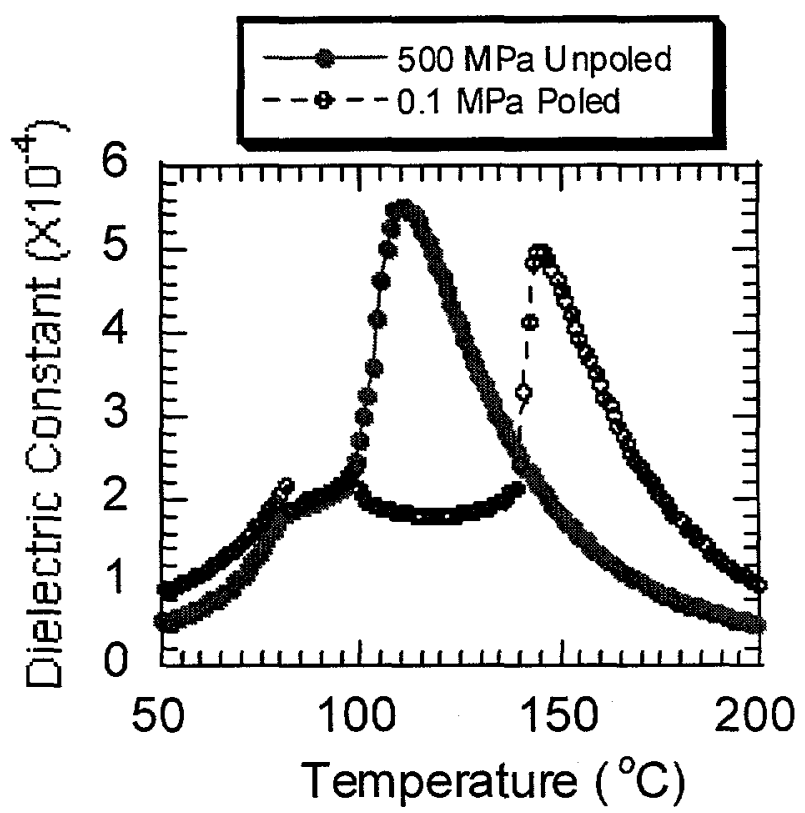

Fig. 4. Dielectric Constant versus temperature for Unpoled SCPMN crystal at $500 \mathrm{MPa}$ and poled crystal at $0.1 \mathrm{MPa}$ hydrostatic pressure.

High frequency impedance analysis was performed on hot-pressed PZT-5A and SCPMN samples of $10 \mathrm{~mm}$ $X 10 \mathrm{~mm} X 1 \mathrm{~mm}$ dimension. Resonant and antiresonant frequencies of roughly $200 \mathrm{kHz}$ and 165 $\mathrm{kHz}$ for the PZT sample and $130 \mathrm{kHz}$ and $145 \mathrm{kHz}$ for the SCPMN sample were measured using 0.5 volt ac drive voltages. A planar coupling coefficient of -0.62 was calculated for the hot-pressed PZT-5A sample. This value is in reasonable agreement with the planar coupling coefficient of -0.60 measured for slightly lower density, commercial [8] PZT-5A material. Impedance spectra for the PZT - 5A specimen exhibited single sharp resonance behavior, while spectra for our SCPMN had more noise. High voltage impedance analysis with larger ac fields ranging from $0.01 \mathrm{kV} / \mathrm{cm}$ to $2 \mathrm{kV} / \mathrm{cm}$ was performed. The resonant and antiresonant frequencies of both samples decreased with applied field. The effect of ac drive voltage on a quantity that is directly proportional to the planar 
coupling coefficient, specifically, the (resonant frequency - the antiresonant frequency) divided by the resonant frequency, is shown in Fig. 5. The coupling coefficients for both samples increase as the ac drive field increases. The SCPMN sample shattered under the application of $1 \mathrm{kV} / \mathrm{cm}$ ac field. This field value is far less than the $2.7 \mathrm{kV} / \mathrm{cm}$ coercive field level $(2 \mathrm{~Hz})$.

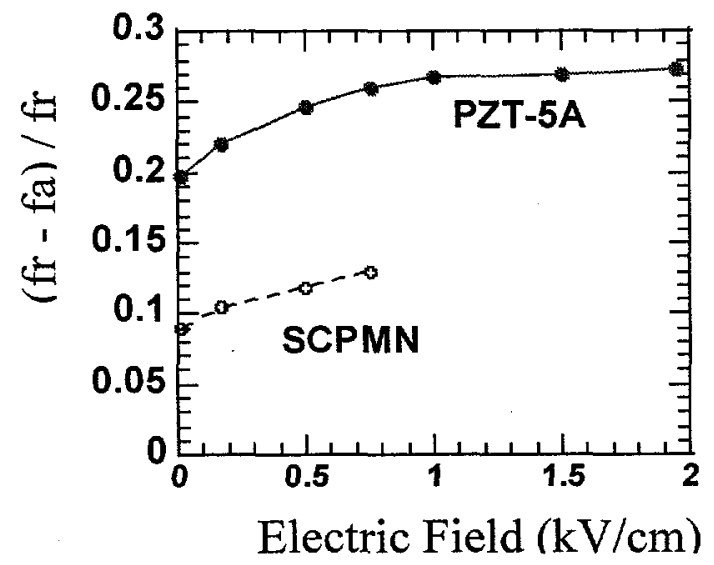

Fig. 5. (Resonant - antiresonant) / resonant frequency behavior versus ac drive field

\section{SUMMARY}

Multilayer actuators were fabricated from single crystal PMN/PT 65/35 (SCPMN) and hot-pressed PZT$5 \mathrm{~A}$ materials using essentially identical procedures. While $25^{\circ} \mathrm{C}, 20 \mathrm{kV} / \mathrm{cm}$ displacements for $1.25 \mathrm{~mm}$ high SCPMN multilayer actuators were $3 \mu \mathrm{m}$, the displacement for the PZT-5A MLAs was $1.1 \mu \mathrm{m}$. Unipolar $20 \mathrm{kV} / \mathrm{cm}$ displacements were approximately $3.4 \mu \mathrm{m}$ between $50^{\circ} \mathrm{C}$ and $75^{\circ} \mathrm{C}$ for the SCPMN MLAs. The reason for the limited change in displacement with temperature was that while the effective piezoelectric constant associated with polarization orientation in the rhombohedral phase increased, the field at which the low displacement tetragonal phase was induced also decreased. We have shown that there is a decrease in Curie point of $4.5^{\circ} \mathrm{C} / 0.1 \mathrm{GPa}$ for SCPMN by measurements from 0 to $2.0 \mathrm{GPa}$ pressure. The rhombohedral to tetragonal phase transition behavior was dependent on thermal and electrical history. Abrupt changes in dielectric constant were observed for poled samples at both the unpoled $\mathrm{R}$ to $\mathrm{T}$ transformation temperature $\left(72^{\circ} \mathrm{C}\right.$ to $\left.80^{\circ} \mathrm{C}\right)$ and at temperatures that were $12^{\circ} \mathrm{C}$ to $18^{\circ} \mathrm{C}$ higher. Hydrostatic pressures as large as $500 \mathrm{MPa}$ did not suppress the dual dielectric peak behavior. High voltage impedance analysis indicated a slight increase in planar coupling coefficients as the ac oscillating field was increased from 0 to $0.75 \mathrm{kV} / \mathrm{cm}$ for both SCPMN and hot-pressed PZT-5A samples.

\section{ACKNOWLEDGMENTS}

The authors acknowledge the technical assistance of Mike Barela, Owen Jones, Geoff Brennecka, William Carlen, Don McMillian, Gary Zender, Bonnie McKenzie and David Lange. Enlightening technical discussions with Pendghi Han of H. C. Materials and Carl Vanececke were greatly appreciated. Sandia is a multiprogram laboratory operated by Sandia Corporation, a Lockheed Martin Company, for the United States Department of Energy under contract DEACO4-94AL85000.

\section{REFERENCES}

[1] S-E. Park and T. R. Shrout, "Ultrahigh Strain and Piezoelectric Behavior in Relaxor Based Ferroelectric Single Crystals," J. Appl. Phys., vol. 21, pp. 1804 - 11 June, 1997.

[2] J. Kuwata, K. Uchino, and S. Nomura, "Dielectric and piezoelectric properties of $0.91 \mathrm{~Pb}\left(\mathrm{Zn}_{1 / 3} \mathrm{Nb}_{2 / 3} \mathrm{O}_{3^{-}}\right.$ $0.09 \mathrm{PbTiO}_{3}$ single crystals," Jpn. J. Appl. Phys., vol.21, no.9, pp.1298-1302, 1982.

[3] S-F. Liu, S-E Park, T.T. Shrout and L. Eric Cross, "Electric Field Dependence of Piezoelectric Properties for Rhombohedral $0.955 \mathrm{~Pb}\left(\mathrm{Zn}_{1 / 3} \mathrm{Nb}_{2 / 3}\right) \mathrm{O}_{3}-0.045$ $\mathrm{PbTiO}_{3}$ Single Crystals," J. Appl. Phys., Vol. 85, pp. 2810-14, March 1999.

[4] S. Saitoh, T. Takeuchi, T. Kobayashi, K. Harada, S. Shimanuki, and Y. Yamashita, "A 3.7 MHz Phased Array Probe Using $0.91 \mathrm{~Pb}\left(\mathrm{Zn}_{1 / 3} \mathrm{Nb}_{2 / 3}\right) \mathrm{O}_{3}-0.09 \mathrm{PbTiO}_{3}$ Single Crystal," IEEE Trans. Ultrason., Ferroelectr., Freq. Contr., vol.46, p. 414-21, March, 1999 [5] J. DeJaco, J. Lindberg, and F. Nussbaum, "Naval Sonar Transducer Requirements," Piezoelectric Crystal Planning Workshop," Washington, DC, May 14-16, 1997.

[6] G.A. Samara, E.L. Venturini and V. H. Schmidt, "The Dielectric Properties and Phase Transitions of $\left[\mathrm{Pb}\left(\mathrm{Zn}_{1 / 3} \mathrm{Nb}_{2 / 3}\right) \mathrm{O}_{3}\right]_{0.905}\left(\mathrm{PbTiO}_{3}\right)_{0.095}$ : Influence of Pressure," Phys. Rev. (submitted).

[7] G.A. Samara, "Pressure and Temperature Dependences of the Dielectric Properties of the Perovskites $\mathrm{BaTiO}_{3}$ and $\mathrm{SrTiO}_{3}$," Phys. Rev., vol. 151, pp. 378-86 Nov. 1966.

[8] ] Morgan Matroc, Inc., Electro Ceramics Division, Guide to Modern Piezoelectric Ceramics. 